\title{
Stock Market Liquidity And Dividend Policy In Korean Corporations
}

Jeong Hwan Lee, Hanyang University, South Korea

Bohyun Yoon, Kangwon National University, South Korea

\begin{abstract}
The liquidity hypothesis predicts a negative relationship between stock liquidity and dividend payout propensity, i.e., a firm will decide to pay dividends to compensate for the liquidity demand of investors. This study comprehensively examines whether the liquidity hypothesis applies to the sample of Korean firms listed in the KOSPI and KOSDAQ markets. The main results of this paper are as follows. First, the dividend policy in Korean firms does not support the liquidity hypothesis, contradictory to the existing empirical studies. Next, the explanatory power of the liquidity hypothesis is even weaker for the KOSDAQ market, inconsistent with international evidence. Finally, even when we focus on the firm-year observations with non-negligible dividend payments, the liquidity hypothesis does not explain the dividend policy of Korean firms either. Our findings significantly contribute to the literature by robustly confirming the very limited role of the liquidity hypothesis for Korean financial markets.
\end{abstract}

Keywords: Liquidity Hypothesis; Dividend Policy; Korean Firms

\section{INTRODUCTION}

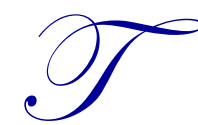

he liquidity hypothesis predicts a negative relationship between a firm's stock liquidity and its dividend payout propensity (Banerjee, Gatchev, \& Spindt 2007). The hypothesis highlights pervasive trading frictions in the market, which cause investors to prefer more liquid stock. Investors have to bear trading costs, and they either have to make a price concession for an immediate execution or they have to wait until optimal execution of their trades. Stocks that pay dividends allow investors to satisfy their liquidity demands with limited or no trading, and hence enable them to avoid trading frictions.

This study analyzes whether Korean corporations pay dividends to meet investors' liquidity demand. This liquidity hypothesis is largely unexamined in the Korean market, while a number of studies verify its significance in the U.S. (Banerjee et al. 2007) and international markets (Griffin 2010). One exception is Kim (2016), who supports the liquidity hypothesis in the KOSPI market with his restrictive empirical model.

Unlike the existing studies, we comprehensively examine the validity of the liquidity hypothesis in Korean firms by (1) employing a rich set of control variables; (2) using various definitions of dividend payout choices; and (3) considering the two major Korean financial markets altogether, the KOSPI and KOSDAQ markets. In particular, we take into account the effect of firms' life cycle (DeAngelo, DeAngelo, \& Stulz 2006), adopt another dividend payout measure emphasizing the role of dividends as a liquidity supplier, and test the liquidity hypothesis in the entire Korean market as well as the KOSPI and the KOSDAQ markets separately.

Our empirical analysis presents a number of interesting results. Most of all, our findings suggest a quite limited explanatory power of the liquidity hypothesis in describing the dividend policy of the Korean firms. Even for the case of stock turnover rate, the most widely used stock liquidity measure, we are not able to validate the liquidity hypothesis for all of our empirical models. Furthermore, we confirm that this liquidity hypothesis has more severe difficulty explaining dividend policy in the KOSDAQ market. The use of another dividend payout measure, which highlights the role of dividend payments as a tool to satisfy investors' liquidity demand, does not change our main findings. 
This paper contributes to the literature in a number of aspects. Most of all, our analysis robustly confirms the restrictive role of the liquidity hypothesis in the Korean market, contradictory to the recent empirical findings such as Kim (2016). Furthermore, to our knowledge, this is the first study that tests the significance of the liquidity hypothesis in the KOSDAQ market. This paper also provides a piece of empirical evidence against the liquidity hypothesis in the international market; in fact, some countries such as Canada, Brazil, and Mexico are shown to have negative relationships between stock liquidity measures and dividend payout probability, unlike ours.

This paper proceeds as follows. Chapter II reviews the relevant literature and develops a testable hypothesis. Chapter III depicts our sample selection and empirical models. Chapter IV documents the estimation results. Chapter V concludes.

\section{LITERATURE REVIEW AND HYPOTHESES}

\section{Literature Review}

While the classic work of Miller and Modigliani (1961) formulated their famous dividend irrelevance theory, their propositions do not explain why companies, investment analysts, and investors are so interested in dividend announcements. To reconcile this puzzling empirical regularity, a number of economic arguments have been proposed and tested since Miller and Modigliani (1961). One strand of literature highlights the importance of asymmetric information between managers and shareholders (e.g., Bhattacharya 1979; Miller and Rock 1985), and pays attention to the signaling effect of dividend payments. Another strand of literature emphasizes the role of dividend payout as a device to reduce overinvestment by managers; large dividend payout reduces the free cash flow (Easterbrook 1984; Jensen 1986).

The life cycle aspect of dividend policy recently emerged as a key determinant in dividend policy. DeAngelo et al. (2006) documented that the mix of earned versus contributed capital in a firm's equity capitalization critically affects the initiation and continuation of dividend payout decisions. The equity capitalization of mature firms is largely composed of their retained earnings; DeAngelo et al. (2006) reported a higher propensity of cash dividends for these mature companies. Denis and Osobov (2008) documented international evidence supporting the hypothesis as well. This life cycle perspective of dividend decisions, while very intuitive, is nonetheless a significant departure from the existing theories.

This paper is most closely related to the literature examining how firm characteristics affect dividend payout choices, especially from the perspective of investors' liquidity demand. This liquidity hypothesis focuses on pervasive trading frictions in the market, which leads one to prefer more liquid stocks. Managers pay dividends to satisfy the liquidity needs of investors. Therefore, such liquidity consideration is more significant for stocks that are thinly traded, for which investors may either have to wait a long time for a buyer or agree to a potentially lower price. In fact, the survey of Dong, Robison, \& Veld (2005) shows that retail investors want dividends, partly due to the lower costs of cashing in dividends compared to the trading costs in selling stocks. Banerjee et al. (2007) provide empirical evidence arguing for this liquidity hypothesis in the U.S. financial market. Griffin (2010) found international evidence supporting the liquidity hypothesis in Canada, Mexico, and Brazil.

Kim (2016) is the unique study that examined whether the liquidity hypothesis explains the dividend policy in the Korean market. He used the turnover rate of each stock as the representative liquidity measure, and finds a negative relationship between stock liquidity and dividend payout propensity. Kim (2016) also pointed out that this tendency has become more significant in recent years. Yet, the empirical models of Kim (2016) may not properly control the life cycle aspect of dividend payout policy, and may not robustly consider the prevailing low dividend yield in Korean corporations. The other important stock market, KOSDAQ, is not examined in his work, either.

\section{Hypothesis Development}

As illustrated in the previous section, the liquidity hypothesis provides the following testable implications.

H0: The measures of stock liquidity are negatively related to dividend payout propensity. 
This paper examines this liquidity hypothesis more comprehensively in the Korean market. For this purpose, we modify the above empirical hypothesis as follows.

H1: If the liquidity hypothesis holds, the measures of stock liquidity are negatively related to dividend payout propensity even after controlling for the life cycle aspect of firms.

H2: If the liquidity hypothesis holds, the measures of stock liquidity are negatively related to dividend payout propensity in the KOSDAQ market.

H3: If the liquidity hypothesis holds, the measures of stock liquidity are negatively related to dividend payout propensity for the firms with non-negligible dividend yields.

The first hypothesis, $H 1$, is closely associated to the recent theoretical development in dividend policy, the life cycle theory of firms. A number of empirical studies confirm the validity of the life cycle theory in dividend payout decisions. See DeAngelo et al. (2006) for the U.S. market evidence and Denis \& Osolov (2008) for the international market evidence. However, the existing studies that test the liquidity hypothesis in the Korean market do not properly control for the life cycle aspect of firms (Kim 2016).

The second hypothesis, H2, is closely associated with recent international evidence. Griffin (2010) argued that the negative relationship between stock liquidity and dividends paid is more significant for small/less profitable firms. If the liquidity hypothesis applies well for KOSPI firms, as in Kim (2016), the hypothesis is highly likely to explain the KOSDAQ firms that consist of relatively small and less profitable firms.

The third hypothesis, $H 3$, is tightly related to prevailing low dividend yields in Korean corporations. The liquidity hypothesis argues that a firm pays dividends to meet investors' liquidity needs. However, Korean firms are widely known to pay quite low levels of dividends, which is not easily reconciled with the role of dividend payout satisfying the liquidity demand of investors. If the liquidity hypothesis indeed has some explanatory power, the firm's decision of a significant dividend payout is more closely related to the stock liquidity measures.

\section{Sample Selection and Empirical Strategy}

\section{Selection of Samples}

This study chooses the sample firms listed in the KOSPI and KOSDAQ markets between 1999 and 2015. We use the WISEfn database to obtain financial statements of the sample firms. The sample period is deliberately chosen because this sample period not only allows us to minimize the potential influence of the East Asian Crisis of 1997, but it has also been established as the period in which the liquidity hypothesis strongly holds (Kim 2016). We exclude financial and utility firms due to their distinctive regulatory environments, which may enforce or restrict dividend payouts. To properly capture the life cycle aspect of the firms, we exclude the firm year-observations with negative earned equity. Each variable is winsorized at a $1 \%$ level. We further remove the sample firms with less than 30 days of trading in a year. The final sample consists of 18,516 firm year observations for 2,173 firms.

\section{Measurement of Stock Liquidity}

We define four different stock liquidity proxy variables in line with Banerjee et al. (2007). The first one is turnover rate, which is defined as the ratio of shares traded to shares outstanding $\left(T U R N_{i t}\right.$ ). Benerjee et al. (2007) and Kim (2016) use the turnover rate as the representative measure of stock liquidity in their analyses. The next one is the illiquidity measure of Amihud (2002), which is calculated as the average ratio of the absolute daily return to daily dollar volume (ILLIQ $\mathrm{it}_{\mathrm{it}}$. The third one is the proportion of days with zero traded volume as an inverse measure of trading activity $\left(\mathrm{NOTRD}_{\mathrm{i}, \mathrm{t}}\right)$. The last variable is the annual traded volume in the stock $\left(\mathrm{VOL}_{\mathrm{it}}\right)$. Table 1 summarizes the definition of liquidity measures and their predicted sign of correlations with dividend payout propensity. 
Table 1. Liquidity Measures and Expected Signs

\begin{tabular}{l|l|c}
\hline \multicolumn{1}{c}{ Measures } & \multicolumn{1}{c}{ Definition } & Sign \\
\hline TURN $_{i, t}$ & Common Shares Traded/ Common Shares Outstanding & Negative $(-)$ \\
\hline ILLIQ $_{\mathrm{i}, \mathrm{t}}$ & Annual Average: Absolute Return/Trading Volume & Positive $(+)$ \\
\hline NOTRD $_{\mathrm{i}, \mathrm{t}}$ & The proportion of days with no trading volume for each year & Positive $(+)$ \\
\hline VOL $_{i, \mathrm{t}}$ & Logarithm of Price $\mathrm{x}$ Common Shares Traded & Negative $(-)$ \\
\hline
\end{tabular}

\section{Empirical Model}

$$
\begin{aligned}
D V_{i, t}= & \operatorname{logit}\left(\beta_{0}+\beta_{1} \text { LIQUIDITY }_{i t}+\beta_{2} \text { STOCK }_{-} P_{i t}+\beta_{3} M B_{i t}+\beta_{4} S A L E G_{i t}+\beta_{5} R O A_{i t}+\beta_{6} L E V_{i t}\right. \\
& \left.+\beta_{7} \text { CASH }_{i t}+\beta_{8} R E / T E_{i t}+\epsilon_{i t}\right)
\end{aligned}
$$

The dependent variable of our model is $\mathrm{DV}_{\mathrm{it}}$, indicating whether an individual firm pays dividends for the fiscal year t. We use two different measures of $\mathrm{DV}_{\mathrm{it}}$. The first measure, $\mathrm{DV} 0_{\mathrm{it}}$, is a standard measure in the literature, and equals one if the firm pays cash dividends and zero otherwise. The second measure, $\mathrm{DV} 1_{\mathrm{it}}$, captures the significance of dividend payments in supplying liquidity. To be precise, the variable is equal to one if a firm's dividends to total asset ratio is greater than $1 \%$, and zero if a firm pays no dividends. All other observations are treated as missing. Because the dependent variable is a binary one in our model, we adopt the logistic regression models to estimate equation (1) in the following analyses.

The independent variables consist of the liquidity measures above LIQUIDITY $_{\text {it }}$ and other control variables. The first set of control variables reflects the size, profitability, and growth opportunities of firms. For a given year $t$ and for each firm $i$, the measure of firm size (STOCK_ $\mathrm{P}_{\mathrm{i}, \mathrm{t}}$ ) is equal to the percentage of firms from the KOSPI and KOSDAQ markets with market capitalization lower than the firm i's market capitalization. The firm size is expected to have a positive correlation $(+)$ with dividend payout probability because large firms tend to have limited investment opportunities (Miller and Modigliani 1961). The market to book asset ratio $\left(\mathrm{MB}_{\mathrm{it}}\right)$ and the sales growth rate $\left(\mathrm{SALEG}_{\mathrm{it}}\right)$ capture the firm's growth opportunities as well, which implies negative coefficients (-) on these variables. The market firm value is total assets minus book value of equity plus market value of equity. The sales growth rate is defined as this period's sales less the previous period's sales divided by the previous period's sales. The return on asset $\left(\mathrm{ROA}_{\mathrm{it}}\right)$ is defined as the ratio of earnings before interest and tax to the total assets. The signaling theory (Bhattacharya 1979) predicts a positive $(+)$ correlation of ROA with dividend payout propensity. The next two variables control the effect of a firm's financing conditions on its dividend policy. A large book leverage ratio implies a significant interest burden to the firm, which potentially reduces its dividend payments. Large accumulated cash stock points to strong cash saving incentives. In other words, it suggests that a firm tends to retain cash rather than pay them out as dividends. Accordingly, we expect negative coefficients (-) on the book leverage ratio $\left(\mathrm{LEV}_{\mathrm{it}}\right)$ and cash to asset ratio $\left(\mathrm{CASH}_{\mathrm{it}}\right)$. Lastly, we control for the life cycle aspect of firms by introducing the retained earnings to total equity ratio ( $\mathrm{RE} / \mathrm{TE}_{\mathrm{it}}$ ). DeAngelo et al. (2006) expected a positive relation (+) between the RE/TE ratio and dividend payout propensity. Table 2 summarizes our construction of variables and their expected signs in equation (1).

\begin{tabular}{|c|c|c|}
\hline Variables & Definition & Sign \\
\hline $\mathrm{DV}_{\text {it }}$ & Equal to 1 if the firm pays dividend and 0 otherwise & N.A. \\
\hline $\mathrm{DV} 1_{\text {it }}$ & Equal to 1 if dividends/assets $>1 \%$, and 0 if dividends/assets $=0 \%$ & N.A. \\
\hline STOCK_P ${ }_{\text {it }}$ & $\begin{array}{l}\text { The percentage of firms in the KOSPI and KOSDAQ markets with market } \\
\text { capitalization lower than the market capitalization of the firm. }\end{array}$ & Positive $(+)$ \\
\hline $\mathrm{MB}_{\mathrm{it}}$ & (Total assets -Book Equity+ Market Equity)/Total Assets & Negative (-) \\
\hline SALEG $_{\text {it }}$ & $(\operatorname{Sales}(\mathrm{t})-$ Sales $(\mathrm{t}-1)) /$ Sales $(\mathrm{t}-1)$ & Negative (-) \\
\hline $\mathrm{ROA}_{i t}$ & Earnings before Interest and Tax/ Total Assets & Positive $(+)$ \\
\hline $\mathrm{LEV}_{\text {it }}$ & Total Debt Obligations/ Total Assets & Negative (-) \\
\hline $\mathrm{CASH}_{\mathrm{it}}$ & Cash and Cash Equivalents/Total Assets & Negative (-) \\
\hline $\mathrm{RE} / \mathrm{TE}_{\mathrm{it}}$ & Retained Earnings/Common Equity & Positive $(+)$ \\
\hline
\end{tabular}

Table 2. Definition of Variables and Expected Sign 


\section{EMPIRICAL RESULTS}

\section{Descriptive Statistics and Correlation Analysis}

Table 3 presents the summary statistics for the variables used in our estimation. It reports the mean and standard deviation of each variable for the entire sample, the sample of the KOSPI market, and the sample of the KOSDAQ market. See Tables 1 and 2 for the definition of variables.

Table 3 provides a couple of interesting results. Most of all, the table confirms the prevailing low dividend yield in the Korean corporations. While the firms with dividend payout account for $69.4 \%$ of the entire sample, this percentage drops significantly to $52.7 \%$ if we focus on the firm-year observations with non-negligible dividend payments (dividend/total assets $>1 \%$ ). In fact, 12,854 firm-year observations have non-zero dividends, but only 6,263 firms report their dividends-asset ratio as greater than $1 \%$. This finding is consistent with the prevailing low dividend yields in Korean corporations; a number of firms pay a very small amount in dividends. Next, the table shows that the firms in the KOSDAQ market tend to be small and have better investment opportunities. While the firms in the KOSDAQ market show lower market capitalization (see STOCK_P), they have a larger market-to-book asset ratio (MB) and higher sales growth rate (SALESG). As expected in the existing theories, the firms in the KOSDAQ market show smaller dividend payout propensity (DV0 and DV1).

Table 3. Descriptive Statistics $(\mathrm{N}=18,516)$

\begin{tabular}{|c|c|c|c|c|c|c|}
\hline \multirow{2}{*}{ Market Variables } & \multicolumn{2}{|c|}{$\operatorname{ALL}(\mathrm{N}=18,516)$} & \multicolumn{2}{|c|}{ KOSPI $(\mathbf{N}=\mathbf{8 , 3 2 7})$} & \multicolumn{2}{|c|}{ KOSDAQ $(\mathrm{N}=10,194)$} \\
\hline & Mean & S.D. & Mean & S.D. & Mean & S.D. \\
\hline DV0 (\%) & 69.48 & 46.05 & 80.41 & 39.69 & 60.44 & 48.90 \\
\hline DV1 $(\%)$ & 52.67 & 49.93 & 62.71 & 48.36 & 46.60 & 49.89 \\
\hline TURN & 3.02 & 5.28 & 2.22 & 4.21 & 3.69 & 5.92 \\
\hline ILLIQ & 56.98 & 365.55 & 9.08 & 49.57 & 96.12 & 487.21 \\
\hline NOTRD (\%) & 0.73 & 4.26 & 0.578 & 2.72 & 0.86 & 5.19 \\
\hline VOL & 5.12 & 1.79 & 5.33 & 1.92 & 4.96 & 1.66 \\
\hline STOCK_P (\%) & 53.88 & 28.41 & 65.47 & 26.90 & 44.42 & 26.01 \\
\hline $\mathrm{MB}$ & 1.12 & 0.67 & 0.97 & 0.52 & 1.24 & 0.74 \\
\hline ROA (\%) & 5.70 & 6.89 & 5.67 & 5.90 & 5.73 & 7.61 \\
\hline SALESG (\%) & 13.28 & 38.37 & 9.84 & 32.46 & 16.10 & 42.38 \\
\hline CASH (\%) & 16.92 & 14.81 & 12.71 & 11.48 & 20.36 & 16.27 \\
\hline $\operatorname{LEV}(\%)$ & 40.89 & 18.91 & 44.06 & 18.46 & 38.31 & 18.89 \\
\hline RE TE $(\%)$ & 47.45 & 24.10 & 47.41 & 24.85 & 47.48 & 23.48 \\
\hline
\end{tabular}

Note: Refer to Table 1 and Table 2 for the definition of variables. Mean and S.D. indicate the sample average and standard deviation, respectively.

In Table 4, we document the pairwise correlation coefficients among our variables of interests. Tables 1 and 2 include the definitions of these variables. The correlations reported here do not strongly support the liquidity hypothesis. For instance, the correlation between the turnover rate and dividend payout propensity is, at best, -0.13 , which is quite small compared to the strong correlations of the ROA and the RE/TE ratio with dividend payments $(>0.3)$. In this table, the NOTRD and ILLIQ variables are even negatively correlated with dividend payout propensity, contradictory to the prediction of the liquidity hypothesis. All of these correlations suggest weak explanatory power of the liquidity hypothesis in the Korean market. 
Table 4. Pairwise Correlation Coefficients ( $\mathrm{N}=18,516)$

\begin{tabular}{|c|c|c|c|c|c|c|c|c|c|c|c|c|c|}
\hline Correlation & DV0 & DV1 & TURN & ILLIQ & NOTRD & DVOL & STOCKP & MB & ROA & SALESG & CASH & LEV & RE/TE \\
\hline DV0 & 1.00 & & & & & & & & & & & & \\
\hline DV1 & 1.00 . & 1.00 & & & & & & & & & & & \\
\hline TURN & -0.13 & -0.11 & 1.00 & & & & & & & & & & \\
\hline ILLIQ & -0.03 & -0.03 & -0.05 & 1.00 & & & & & & & & & \\
\hline NOTRD & -0.03 & -0.05 & -0.04 & 0.47 & 1.00 & & & & & & & & \\
\hline VOL & -0.00 & -0.00 & 0.28 & -0.28 & -0.20 & 1.00 & & & & & & & \\
\hline STOCK_P & 0.23 & 0.27 & -0.09 & -0.16 & -0.08 & 0.60 & 1.00 & & & & & & \\
\hline $\mathrm{MB}$ & -0.08 & 0.03 & 0.10 & -0.05 & 0.00 & 0.43 & 0.35 & 1.00 & & & & & \\
\hline ROA & 0.37 & 0.50 & -0.03 & -0.01 & -0.01 & 0.13 & 0.28 & 0.25 & 1.00 & & & & \\
\hline SALESG & 0.04 & 0.07 & 0.09 & 0.00 & 0.01 & 0.09 & 0.11 & 0.18 & 0.27 & 1.00 & & & \\
\hline $\mathrm{CASH}$ & 0.01 & 0.14 & 0.05 & -0.02 & -0.02 & 0.06 & 0.02 & 0.26 & 0.15 & 0.03 & 1.00 & & \\
\hline LEV & -0.13 & -0.31 & 0.03 & 0.05 & 0.05 & 0.06 & -0.03 & -0.10 & -0.18 & 0.05 & -0.46 & 1.00 & \\
\hline $\mathrm{RE} / \mathrm{TE}$ & 0.37 & 0.44 & -0.27 & 0.01 & -0.00 & -0.08 & 0.07 & -0.02 & 0.32 & -0.09 & 0.12 & -0.22 & 1.00 \\
\hline
\end{tabular}

Note: Refer to Table 1 and Table 2 for the definition of variables.

\section{Multivariate Logit Analysis}

In this section, we implement multivariate logit models to rigorously test the validity of the liquidity hypothesis for Korean firms. Table 5 reports the logit estimation results of equation (1) for the entire sample of firms and the estimated coefficients and z-statistics (in parenthesis) for our two different measures of dividend payout propensity, DV0 and DV1. The definition of variables is described in Tables 1 and 2.

Table 5 clearly shows that the liquidity hypothesis has limited explanatory power for the dividend policy in Korea. For example, the turnover rate, the representative measure of stock liquidity in the literature, has no significant relationship with dividend propensity (Models (1) and (4)). The illiquidity measure, ILLIQ, and the proportion of no trading date, NOTRD, show even negative correlations with the dividend payout probability in contrast to the liquidity hypothesis prediction. Only the trading volume measure shows the expected correlations.

The result argues against the recent empirical finding of Kim (2016), whose analysis shows that the liquidity hypothesis holds very well even in terms of turnover rate and the proportion of no trading date. This differing result seems to be caused by the choice of our controlling variables. Kim (2016) does not incorporate the life cycle aspect of the corporation, RE/TE, as a control variable, which is strongly significant in our multivariate logit analysis. In fact, the turnover rate has significantly negative correlations with dividend payout propensity in the absence of the RE/TE variable, while we do not report the estimation result in detail.

Table 5 also suggests that, if we focus on the firm-year observations with non-negligible dividend payments, the liquidity hypothesis has lower explanatory powers in dividend payments decisions. In Models (5) and (7), the turnover rate shows even a positive correlation and the proportion of no trading days shows a significantly negative correlation with dividend payout propensity. This contradicting result undermines the validity of the liquidity hypothesis in the Korean market as well. 
Table 5. Multivariate Logit Model Estimation: All

\begin{tabular}{|c|c|c|c|c|c|c|c|c|}
\hline \multirow{2}{*}{ Model } & \multicolumn{4}{|c|}{ DV0 } & \multicolumn{4}{|c|}{ DV1 } \\
\hline & (1) & (2) & (3) & (4) & (5) & (6) & (7) & (8) \\
\hline \multirow{2}{*}{ TURN } & -0.01 & & & & 0.01 & & & \\
\hline & $(-1.2)$ & & & & $(1.2)$ & & & \\
\hline \multirow{2}{*}{ ILLIQ } & & -0.00 & & & & 0.00 & & \\
\hline & & $(-0.0)$ & & & & $(0.4)$ & & \\
\hline \multirow{2}{*}{ NOTRD } & & & $-0.01^{*}$ & & & & $-0.02^{* * *}$ & \\
\hline & & & $(-1.9)$ & & & & $(-2.7)$ & \\
\hline \multirow{2}{*}{ VOL } & & & & $-0.14^{* * *}$ & & & & $-0.18^{* * *}$ \\
\hline & & & & $(-6.1)$ & & & & $(-6.3)$ \\
\hline \multirow{2}{*}{ STOCK_P } & $0.02^{* * *}$ & $0.02^{* * *}$ & $0.02^{* * *}$ & $0.03^{* * *}$ & $0.02^{* * *}$ & $0.02^{* * *}$ & $0.02^{* * * *}$ & $0.02^{* * *}$ \\
\hline & $(14.4)$ & $(14.4)$ & $(14.4)$ & $(15.5)$ & $(10.2)$ & $(10.1)$ & $(10.0)$ & $(11.5)$ \\
\hline \multirow{2}{*}{ MB } & $-0.92^{* * *}$ & $-0.93^{* * *}$ & $-0.92^{* * *}$ & $-0.83^{* * *}$ & $-0.75^{* * *}$ & $-0.75^{* * *}$ & $-0.74^{* * *}$ & $-0.63^{* * *}$ \\
\hline & $(-15.2)$ & $(-15.3)$ & $(-15.2)$ & $(-13.8)$ & $(-10.3)$ & $(-10.3)$ & $(-10.2)$ & $(-8.7)$ \\
\hline \multirow{2}{*}{ SALESG } & 0.00 & 0.00 & 0.00 & 0.00 & -0.00 & -0.00 & -0.00 & -0.00 \\
\hline & $(0.3)$ & $(0.2)$ & $(0.3)$ & $(0.0)$ & $(-1.0)$ & $(-1.0)$ & $(-0.9)$ & $(-1.2)$ \\
\hline \multirow{2}{*}{ ROA } & $0.13^{* * *}$ & $0.13^{* * *}$ & $0.13^{* * *}$ & $0.13^{* * *}$ & $0.17^{* * *}$ & $0.17^{* * *}$ & $0.17^{* * *}$ & $0.17^{* * *}$ \\
\hline & $(20.1)$ & $(20.1)$ & $(20.1)$ & $(19.9)$ & $(20.6)$ & $(20.6)$ & $(20.7)$ & $(20.3)$ \\
\hline \multirow{2}{*}{ CASH } & $-0.01^{* *}$ & $-0.01^{* *}$ & $-0.01^{* *}$ & $-0.01^{* *}$ & 0.00 & 0.00 & 0.00 & 0.00 \\
\hline & $(-2.3)$ & $(-2.4)$ & $(-2.4)$ & $(-2.0)$ & $(0.1)$ & $(0.1)$ & $(0.1)$ & $(0.5)$ \\
\hline \multirow{2}{*}{ LEV } & $-0.01^{* * *}$ & $-0.01^{* * *}$ & $-0.01^{* * *}$ & $-0.01^{* * *}$ & $-0.03^{* * *}$ & $-0.03^{* * *}$ & $-0.03^{* * *}$ & $-0.03^{* * *}$ \\
\hline & $(-4.6)$ & $(-4.6)$ & $(-4.5)$ & $(-4.1)$ & $(-10.6)$ & $(-10.6)$ & $(-10.5)$ & $(-10.3)$ \\
\hline \multirow{2}{*}{ RE/TE } & $0.03^{* * *}$ & $0.03^{* * *}$ & $0.03^{* * *}$ & $0.03^{* * *}$ & $0.03^{* * *}$ & $0.03^{* * *}$ & $0.03^{* * *}$ & $0.03^{* * *}$ \\
\hline & $(17.0)$ & $(17.9)$ & $(17.9)$ & $(17.4)$ & $(14.1)$ & $(14.5)$ & $(14.5)$ & $(14.0)$ \\
\hline \multirow{2}{*}{ Intercept } & $-0.55^{* * *}$ & $-0.59^{* * *}$ & $-0.58^{* * *}$ & -0.23 & $-1.14^{* * *}$ & $-1.10^{* * *}$ & $-1.09^{* * *}$ & $-0.61^{* * *}$ \\
\hline & $(-3.5)$ & $(-3.7)$ & $(-3.7)$ & $(-1.3)$ & $(-5.8)$ & $(-5.7)$ & $(-5.7)$ & $(-2.9)$ \\
\hline $\mathrm{N}$ & 18516 & 18516 & 18516 & 18516 & 11923 & 11923 & 11923 & 11923 \\
\hline pseudo $\mathrm{R}^{2}$ & 0.247 & 0.247 & 0.247 & 0.251 & 0.347 & 0.347 & 0.348 & 0.353 \\
\hline
\end{tabular}

Notes: *,**, and *** represent significance at the $90 \%, 95 \%$, and $99 \%$ levels, respectively. The variable definition refers to Table 1 and Table 2 .

Corresponding Z-values are reported in parenthesis.

The coefficients of all other variables are generally in line with the existing literature. The firm size variable (STOCK_P), the profitability variable (ROA), and the life cycle proxy variable (RE/TE) show significantly positive correlations with dividend payout probability, as expected. The market to book asset ratio (MB), cash holdings (CASH), and book leverage (LEV) show a negative relationship with dividend payout propensity, as predicted. The coefficients of sales growth, SALESG, are not statistically significant in contrast to the literature. This might be due to the inclusion of other control variables such as RE/TE and MB, which also capture the future investment opportunity information reflected in the sales growth rate.

Table 6 documents the logit estimation results of equation (1) for the sample of firms in the KOSPI market. It reports the estimated coefficients and z-statistics (in parenthesis) for our two different measures of dividend payout propensity DV0 and DV1. The definitions of variables are documented in Tables 1 and 2.

In contrast to the existing literature, Table 6 does not support the liquidity hypothesis even for the KOSPI market. The turnover rate (TURN), the illiquidity measure (ILLIQ), and the proportion of no trading days (NOTRD) are all statistically insignificant when we use DV0 as our dependent variable. This finding contradicts the analysis of Kim (2016) for the KOSPI market, which presents empirical evidence favoring the liquidity hypothesis. As mentioned above, this discrepancy might be caused by the choice of control variable; Kim's (2016) empirical model does not account for the life cycle aspect of firms, whereas our model does.

Other results in Table 6 are similar to those of Table 5. The explanatory power of the liquidity hypothesis becomes weaker when we consider the firm-year observations with non-negligible dividend payouts; the turnover rate has a positive correlation and the proportion of no trading days has a statistically significant negative correlation with dividend payout probability. The coefficients on other variables are generally in line with those in Table 5. 
Table 6. Multivariate Logit Model Estimation: KOSPI Market

\begin{tabular}{|c|c|c|c|c|c|c|c|c|}
\hline \multirow{2}{*}{ Model } & \multicolumn{4}{|c|}{ DV0 } & \multicolumn{4}{|c|}{ DV1 } \\
\hline & (1) & (2) & (3) & (4) & (5) & (6) & (7) & (8) \\
\hline \multirow{2}{*}{ TURN } & -0.01 & & & & 0.01 & & & \\
\hline & $(-1.5)$ & & & & $(0.5)$ & & & \\
\hline \multirow{2}{*}{ ILLIQ } & & 0.00 & & & & 0.00 & & \\
\hline & & $(0.9)$ & & & & $(0.5)$ & & \\
\hline \multirow{2}{*}{ NOTRD } & & & -0.01 & & & & $-0.07^{* *}$ & \\
\hline & & & $(-0.8)$ & & & & $(-2.4)$ & \\
\hline \multirow{2}{*}{ VOL } & & & & $-0.15^{* * *}$ & & & & $-0.19^{* * *}$ \\
\hline & & & & $(-3.5)$ & & & & $(-3.5)$ \\
\hline \multirow{2}{*}{ STOCK_P } & $0.02^{* * *}$ & $0.02^{* * *}$ & $0.02^{* * *}$ & $0.03^{* * *}$ & $0.02^{* * *}$ & $0.02^{* * *}$ & $0.02^{* * *}$ & $0.03^{* * *}$ \\
\hline & $(8.5)$ & $(8.7)$ & $(8.6)$ & $(9.0)$ & (6.9) & $(6.9)$ & $(6.8)$ & $(7.7)$ \\
\hline \multirow{2}{*}{ MB } & $-0.97^{* * *}$ & $-0.98^{* * *}$ & $-0.98^{* * *}$ & $-0.83^{* * *}$ & $-0.61^{* * *}$ & $-0.61^{* * *}$ & $-0.61^{* * *}$ & $-0.41^{* *}$ \\
\hline & $(-7.9)$ & $(-8.0)$ & $(-8.1)$ & $(-6.5)$ & $(-3.2)$ & $(-3.2)$ & $(-3.2)$ & $(-2.1)$ \\
\hline \multirow{2}{*}{ SALESG } & $0.00^{* * *}$ & $0.00^{* * *}$ & $0.00^{* * *}$ & $0.00^{* * *}$ & $0.00^{*}$ & $0.00^{*}$ & $0.00^{*}$ & $0.00^{*}$ \\
\hline & $(3.1)$ & $(3.0)$ & $(3.0)$ & $(3.0)$ & (1.9) & $(1.9)$ & $(1.9)$ & $(1.8)$ \\
\hline \multirow{2}{*}{ ROA } & $0.14^{* * *}$ & $0.14^{* * *}$ & $0.14^{* * *}$ & $0.14^{* * *}$ & $0.20^{* * *}$ & $0.20^{* * *}$ & $0.20^{* * *}$ & $0.20^{* * *}$ \\
\hline & $(11.5)$ & $(11.5)$ & $(11.4)$ & (11.4) & $(11.0)$ & $(11.1)$ & $(11.0)$ & $(10.8)$ \\
\hline \multirow{2}{*}{$\mathrm{CASH}$} & -0.01 & -0.01 & -0.01 & -0.01 & -0.00 & -0.00 & -0.00 & -0.00 \\
\hline & $(-1.4)$ & $(-1.5)$ & $(-1.5)$ & $(-1.4)$ & $(-0.6)$ & $(-0.6)$ & $(-0.5)$ & $(-0.5)$ \\
\hline \multirow{2}{*}{ LEV } & $-0.02^{* * *}$ & $-0.02^{* * *}$ & $-0.02^{* * *}$ & $-0.02^{* * *}$ & $-0.05^{* * *}$ & $-0.05^{* * *}$ & $-0.05^{* * *}$ & $-0.05^{* * *}$ \\
\hline & $(-5.7)$ & $(-5.8)$ & $(-5.8)$ & $(-5.1)$ & $(-9.5)$ & $(-9.5)$ & $(-9.6)$ & $(-8.9)$ \\
\hline \multirow{2}{*}{ RE/TE } & $0.03^{* * *}$ & $0.03^{* * *}$ & $0.03^{* * *}$ & $0.03^{* * *}$ & $0.03^{* * *}$ & $0.03^{* * *}$ & $0.03^{* * *}$ & $0.03^{* * *}$ \\
\hline & $(9.6)$ & $(10.1)$ & $(10.2)$ & $(9.9)$ & $(7.8)$ & $(8.0)$ & $(8.0)$ & $(7.8)$ \\
\hline \multirow{2}{*}{ Intercept } & 0.44 & 0.35 & 0.40 & $0.61^{* *}$ & -0.45 & -0.45 & -0.32 & -0.10 \\
\hline & (1.6) & $(1.3)$ & $(1.5)$ & $(2.2)$ & $(-1.3)$ & $(-1.3)$ & $(-0.9)$ & $(-0.3)$ \\
\hline $\mathrm{N}$ & 8326 & 8326 & 8326 & 8326 & 4373 & 4373 & 4373 & 4373 \\
\hline pseudo $\mathrm{R}^{2}$ & 0.256 & 0.256 & 0.256 & 0.260 & 0.431 & 0.431 & 0.433 & 0.436 \\
\hline
\end{tabular}

Notes: *, **, and *** represent significance at the $90 \%, 95 \%$, and $99 \%$ levels, respectively. The variable definition refers to Table 1 and Table 2 . Corresponding $\mathrm{Z}$-values are reported in parenthesis.

Table 7 shows the logit estimation results of equation (1) for the sample of firms in the KOSDAQ market. It contains the estimated coefficients and z-statistics (in parenthesis) for our two dividend payout propensity measures, DV0 and DV1. The definition of variables is included in Tables 1 and 2.

Table 7 provides empirical evidence strongly against the liquidity hypothesis in the KOSDAQ market. The turnover rate (TURN) shows positive correlations with the dividend payout propensity, and its coefficient becomes statistically significant when we consider the non-negligible dividend payments in Model (8). Moreover, the proportion of no trading days, NOTRD, is negatively related to dividend payout choices, in contrast to the prediction of the liquidity hypothesis. The negative correlations are significant at the 95\% level in Models (3) and (7). Both findings indicate the liquidity hypothesis's limited role in the KOSDAQ sample; its explanatory power appears even weaker in the KOSDAQ market than in the KOSPI market.

Other coefficients in Table 7 are similar to those of previous tables. The estimated coefficients on the STOCK_P, $\mathrm{ROA}$, and RE/TE variables are positive and statistically significant, as expected. The book leverage and market-tobook asset ratios are negatively related to the probability of dividend payout in line with the prior analyses. 
Table 7. Multivariate Logit Model Estimation: KOSDAQ Market

\begin{tabular}{|c|c|c|c|c|c|c|c|c|}
\hline \multirow{2}{*}{ Model } & \multicolumn{4}{|c|}{ DV0 } & \multicolumn{4}{|c|}{ DV1 } \\
\hline & (1) & (2) & (3) & (4) & (5) & (6) & (7) & (8) \\
\hline \multirow{2}{*}{ TURN } & 0.01 & & & & $0.02^{* *}$ & & & \\
\hline & $(1.0)$ & & & & $(2.5)$ & & & \\
\hline \multirow{2}{*}{ ILLIQ } & & 0.00 & & & & 0.00 & & \\
\hline & & $(0.4)$ & & & & $(0.2)$ & & \\
\hline \multirow{2}{*}{ NOTRD } & & & $-0.01^{* *}$ & & & & $-0.02^{* *}$ & \\
\hline & & & $(-2.3)$ & & & & $(-2.4)$ & \\
\hline \multirow{2}{*}{ VOL } & & & & $-0.11^{* * *}$ & & & & $-0.18^{* * *}$ \\
\hline & & & & $(-4.1)$ & & & & $(-5.4)$ \\
\hline \multirow{2}{*}{ STOCK_P } & $0.01^{* * *}$ & $0.01^{* * *}$ & $0.01^{* * *}$ & $0.01^{* * *}$ & $0.00^{*}$ & $0.00^{*}$ & $0.00^{*}$ & $0.01^{* * *}$ \\
\hline & $(4.0)$ & $(4.0)$ & $(3.9)$ & $(5.1)$ & $(1.9)$ & $(1.9)$ & $(1.7)$ & $(3.5)$ \\
\hline \multirow{2}{*}{ MB } & $-0.58^{* * *}$ & $-0.58^{* * *}$ & $-0.57^{* * *}$ & $-0.52^{* * *}$ & $-0.50^{* * *}$ & $-0.49^{* * *}$ & $-0.48^{* * *}$ & $-0.39^{* * *}$ \\
\hline & $(-7.9)$ & $(-7.9)$ & $(-7.7)$ & $(-7.1)$ & $(-6.1)$ & $(-6.0)$ & $(-5.8)$ & $(-4.8)$ \\
\hline \multirow{2}{*}{ SALESG } & -0.00 & -0.00 & -0.00 & -0.00 & -0.00 & -0.00 & -0.00 & -0.00 \\
\hline & $(-0.3)$ & $(-0.2)$ & $(-0.2)$ & $(-0.3)$ & $(-1.1)$ & $(-1.0)$ & $(-1.0)$ & $(-1.3)$ \\
\hline \multirow{2}{*}{ ROA } & $0.13^{* * *}$ & $0.13^{* * *}$ & $0.13^{* * *}$ & $0.13^{* * *}$ & $0.17^{* * *}$ & $0.17^{* * *}$ & $0.17^{* * *}$ & $0.17^{* * *}$ \\
\hline & $(17.1)$ & $(17.0)$ & $(17.1)$ & (16.9) & $(18.3)$ & $(18.3)$ & (18.3) & $(18.1)$ \\
\hline \multirow{2}{*}{$\mathrm{CASH}$} & 0.00 & 0.00 & 0.00 & 0.00 & $0.01^{* * *}$ & $0.01^{* * *}$ & $0.01^{* * *}$ & $0.01^{* * *}$ \\
\hline & $(0.7)$ & $(0.7)$ & $(0.7)$ & $(0.8)$ & $(2.7)$ & $(2.7)$ & $(2.7)$ & $(3.0)$ \\
\hline \multirow{2}{*}{ LEV } & $-0.01^{*}$ & $-0.01^{*}$ & $-0.00^{*}$ & $-0.01^{*}$ & $-0.02^{* * *}$ & $-0.02^{* * *}$ & $-0.02^{* * *}$ & $-0.02^{* * *}$ \\
\hline & $(-1.9)$ & $(-1.9)$ & $(-1.8)$ & $(-1.9)$ & $(-6.2)$ & $(-6.2)$ & $(-6.0)$ & $(-6.3)$ \\
\hline \multirow{2}{*}{ RE/TE } & $0.03^{* * *}$ & $0.03^{* * *}$ & $0.03^{* * *}$ & $0.03^{* * *}$ & $0.03^{* * *}$ & $0.03^{* * *}$ & $0.03^{* * *}$ & $0.03^{* * *}$ \\
\hline & $(14.5)$ & $(14.9)$ & $(14.9)$ & $(14.5)$ & $(11.5)$ & $(11.6)$ & $(11.7)$ & $(11.1)$ \\
\hline \multirow{2}{*}{ Intercept } & $-1.18^{* * *}$ & $-1.14^{* * *}$ & $-1.15^{* * *}$ & $-0.78^{* * *}$ & $-1.58^{* * *}$ & $-1.47^{* * *}$ & $-1.48^{* * *}$ & $-0.88^{* * *}$ \\
\hline & $(-5.9)$ & $(-5.8)$ & $(-5.8)$ & $(-3.5)$ & $(-6.8)$ & $(-6.5)$ & $(-6.5)$ & $(-3.6)$ \\
\hline $\mathrm{N}$ & 10190 & 10190 & 10190 & 10190 & 7550 & 7550 & 7550 & 7550 \\
\hline pseudo $\mathrm{R}^{2}$ & 0.228 & 0.228 & 0.229 & 0.231 & 0.318 & 0.317 & 0.318 & 0.323 \\
\hline
\end{tabular}

Notes: *, **, and *** represent significance at the $90 \%, 95 \%$, and $99 \%$ levels, respectively. The variable definition refers to Table 1 and Table 2 . Corresponding $\mathrm{Z}$-values are reported in parenthesis.

\section{DISCUSSION}

The estimation results in the previous section reject all of our empirical hypotheses developed in Chapter II. Most of all, after controlling for the life cycle aspect of the firm, three out of four liquidity measures do not support the liquidity hypothesis in the Korean market. In particular, the representative stock liquidity measure, the turnover rate, shows statistically insignificant or even significantly positive correlations with dividend payout propensity. This result directly contradicts the empirical findings of Kim (2016), arguing for the liquidity hypothesis in the Korean market. Furthermore, while the existing studies indicate greater explanatory power of the liquidity hypothesis for small firms with better growth opportunities (Griffin 2010), our analysis suggests a less significant role of the liquidity hypothesis in the KOSDAQ market, mainly composed of small/growth firms. Finally, even though we adopt the measure of nonnegligible dividend payouts, the liquidity hypothesis does not explain the dividend policy of the Korean firms either. In fact, the examination of non-negligible dividend payments more strongly rejects the liquidity hypothesis.

In sum, our analysis does not support all of the three empirical hypotheses developed in Chapter II. Our analysis robustly confirms that the liquidity hypothesis has very restrictive explanatory powers in the Korean market.

\section{CONCLUSION}

This paper studied whether the liquidity hypothesis holds well in the Korean market. For a rigorous analysis, we included sample firms from the KOSPI and KOSDAQ markets, set up the empirical model to control for the life cycle theory of dividends, and used two different dividend payout measures. The estimation results from analyzing 18,516 firm-year observations can be summarized as follows: (1) the liquidity hypothesis does not show significant explanatory powers for all of our specifications; (2) the liquidity hypothesis has severe difficulty explaining the 
dividend policies of the firms listed in the KOSDAQ market; (3) the explanatory power of the liquidity hypothesis is even weaker when we focus on the firm-year observations with non-negligible dividend payments.

This work contributes to the literature by comprehensively examining the liquidity hypothesis in Korean firms. The estimation results, in fact, contradict the existing empirical evidence favoring the liquidity hypothesis in the Korean market (Kim 2016). Also, to the best of our knowledge, this is the first study that tests the liquidity hypothesis in the KOSDAQ market. Our consideration of non-negligible dividend payments is novel and necessary to reflect the prevailing low dividend yield in Korean firms. Yet, the liquidity hypothesis does not hold irrespective of our dividend payment variable definitions.

\section{ACKNOWLEDGEMENTS}

This study was supported by 2015 Research Grant from Kangwon National University.

\section{AUTHOR BIOGRAPHIES}

Jeong Hwan Lee. Ph.D., Assistant Professor of Division of Economics and Finance, Hanyang University, 222 Wangsimni-ro, Seoul, Korea. E-mail: jeonglee@hanyang.ac.kr (First Author)

Bohyun Yoon. Ph.D., Assistant Professor, Division of Economics and International Trade, Kangwon National University, 1 Kangwondaehak-gil, Chunchoen-si, Gangwon-do, Korea. E-mail: yoonbo@kangwon.ac.kr (Corresponding Author)

\section{REFERENCES}

Amihud, Y. (2002). Illiquidity and stock returns: cross-section and time-series effects. Journal of financial markets, 5(1), 31-56. Banerjee, S., V.A. Gatchev, \& P.A. Spindt. (2007). Stock market liquidity and firm dividend policy. Journal of Financial and Quantitative Analysis, 42(02), 369-397.

Bhattacharya, S. (1979). Imperfect information, dividend policy, and "the bird in the hand" fallacy. Bell Journal of Economics, 10(1), 259-270.

DeAngelo, H., L. DeAngelo, \& R.M. Stulz. (2006). Dividend policy and the earned/contributed capital mix: a test of the lifecycle theory. Journal of Financial Economics, 81(2), 227-254.

Denis, D.J. and I. Osobov. (2008). Why do firms pay dividends? International evidence on the determinants of dividend policy. Journal of Financial Economics, 89(1), 62-82.

Dong, M., C. Robinson, \& C. Veld. (2005). Why individual investors want dividends. Journal of Corporate Finance, 12(1), 121158.

Easterbrook, F.H. (1984). Two agency-cost explanations of dividends. The American Economic Review, 74(4), 650-659.

Griffin, C.H. (2010). Liquidity and dividend policy: international evidence. International Business Research, $3(3), 3$.

Jensen, M.C. (1986). Agency cost of free cash flow, corporate finance, and takeovers. Corporate Finance, and Takeovers. American Economic Review, 76(2).

Kim, J.W. (2016). The effects of stock liquidity on the firm's dividend policy in korean stock market. Korean Corporation Management Review, 69, 133-157.

Miller, M.H. \& F. Modigliani. (1961). Dividend policy, growth, and the valuation of shares. The Journal of Business, 34(4), 411433.

Miller, M.H. \& K. Rock (1985). Dividend policy under asymmetric information. The Journal of Finance, 40(4), $1031-1051$. 